\title{
Keratinocyte growth factor and coeliac disease
}

\author{
V M Salvati, M Bajaj-Elliott, R Poulsom, G Mazzarella, K E A Lundin, E M Nilsen, \\ $\mathrm{R}$ Troncone, $\mathrm{T} \mathrm{T}$ MacDonald
}

\begin{abstract}
Background-Coeliac disease is characterised by increased epithelial renewal associated with a mucosal $T$ cell response to gliadin. Keratinocyte growth factor (KGF) is produced by cytokine activated gut stromal cells and may be a link between mucosal $T$ cell activation in untreated coeliac disease and epithelial hyperplasia.
\end{abstract}

Aims - To characterise expression of KGF in coeliac disease.

Methods-KGF transcripts in coeliac disease were measured by quantitative competitive reverse transcription-polymerase chain reaction (RT-PCR) and localised using in situ hybridisation. KGF production by gluten reactive $\mathrm{CD} 4+\mathrm{T}$ cell clones was examined. In addition, KGF transcripts were measured following ex vivo challenge of coeliac biopsies with a peptictryptic digest of gliadin.

Results-KGF transcripts were elevated in coeliac biopsies compared with normal controls but were not different from non-coeliac disease controls. By in situ hybridisation, KGF mRNA containing cells were present in the upper half of the lamina propria, most abundantly just under the epithelium. There was no signal from cells within the epithelium. Gluten reactive $T$ cell clones did not make KGF. In vitro challenge of coeliac biopsies generated a strong interferon $\gamma$ response but a specific KGF response could not be detected because of an extremely high number of KGF transcripts in all cultured biopsies.

Conclusions-KGF is overexpressed in coeliac biopsies and in tissues with noncoeliac enteropathy. No evidence was found for KGF production by intraepithelial lymphocytes or lamina propria $\mathrm{T}$ cells. (Gut 2001;49:176-181)

Keywords: coeliac disease; keratinocyte growth factor; mRNA expression

In untreated coeliac disease (CD), transformation of the small intestinal mucosa is one of the most striking examples of immune mediated enteropathy. The characteristic villus atrophy and crypt hyperplasia is in fact mucosal remodelling and tissue growth, in this case expansion of the lamina propria volume with a reduction in epithelial surface area. ${ }^{1}$ The exact sequence of events that leads to the flat mucosa is not known. It has been suggested that immune mediated epithelial damage leads to compensatory crypt hyperplasia ${ }^{2}$ in which the epithelium causes the transformation. On the other hand, expansion of the lamina propria compartment could also be responsible for crypt hypertrophy with unknown events also leading to increased epithelial division.

Normal epithelium renewal is controlled largely by transforming growth factor $\alpha$, epidermal growth factor, and transforming growth factor $\beta$ working in an autocrine fashion within the epithelium. ${ }^{3}$ Subepithelial myofibroblasts and basement membranes are essential for epithelial formation but whether they play a role in controlling basal levels of proliferation is not known. An attractive notion to explain the hyperplasia seen in all forms of gut inflammation is that locally released cytokines increase the production of growth factors from lamina propria stromal cells, which are then mitogenic for epithelial cells. For example, in the stomach, interleukin 1 induced overexpression of hepatocyte growth factor may drive increased epithelial renewal. ${ }^{4}$ In the small bowel and colon, there has been much interest in the role of keratinocyte growth factor (KGF, FGF-7). KGF is a well characterised epithelial mitogen and is produced by cytokine activated mesenchymal cells. ${ }^{5}$ Injection of recombinant $\mathrm{KGF}$ into rats increases gut epithelial proliferation. ${ }^{6} \mathrm{KGF}$ transcripts are abundantly expressed in the mucosa in inflammatory bowel disease (IBD). ${ }^{78}$ In addition, in a model system of $T$ cell mediated crypt hyperplasia, we have shown directly that KGF is involved in increasing epithelial proliferation. ${ }^{9}$ While the majority of evidence suggests that in the gut KGF is made by stromal cells, there is evidence that in mice epithelial $\gamma \delta \mathrm{T}$ cells can also make KGF. ${ }^{10}$ Thus in the case of $\mathrm{CD}$, where the increase in intraepithelial (IEL) $\gamma \delta \mathrm{T}$ cells is well documented, it is highly relevant to determine if $\mathrm{KGF}$ is also expressed by these cells. ${ }^{1112}$

In this study therefore we have analysed KGF in CD to determine if it is overexpressed and the location of KGF mRNA containing cells. In addition, we have attempted to determine if $\mathrm{KGF}$ is made by $\mathrm{T}$ cells. Finally, we carried out experiments to determine if there was induction of excess KGF following gluten challenge ex vivo.

\section{Patients and methods}

PATIENTS

Twenty five patients with active CD, five patients with non-coeliac enteropathy (NCE), and 16 age matched normal controls referred

Abbreviations used in this paper: $\mathrm{CD}$, coeliac disease; KGF (FGF-7), keratinocyte growth factor; IEL, intraepithelial lymphocytes; NCE, non-coeliac enteropathy; RT-PCR, reverse transcription-polymerase chain reaction; IFN- $\gamma$, interferon $\gamma$; IBD, inflammatory bowel disease; LPL, lamina propria $\mathrm{T}$ cells. 
to the Department of Paediatric Gastroenterology and Endoscopy, University Federico II, Naples, for abdominal complaints, growth failure, weight loss, diarrhoea, or vomiting were enrolled. Biopsies from the proximal jejunum were taken by gastroduodenal endoscopy, quickly snap frozen in liquid nitrogen, and stored at $-80^{\circ} \mathrm{C}$ for quantitative reversetranscription polymerase chain reaction (RTPCR) analysis. CD patients (15 females, 10 males) ranged in age from 0.7 to 13.4 years (median 3), patients with NCE (two females, three males) ranged in age from 0.9 to 16 years (median 4), and normal control patients (five females, 11 males) ranged in age from 1.6 to 16.9 years (median 7). The diagnosis of CD was confirmed by ESPGHAN criteria including flattening of villi and increased number of IELs in the initial biopsy, and a prompt clinical response to a gluten free diet. ${ }^{13}$ Normal control patients had no significant abnormality of the small intestinal mucosa and were mainly affected by oesophagitis (12/16), gastritis $(3 / 16)$, or irritable bowel syndrome $(1 / 16)$. Patients with NCE were affected by gastritis and/or duodenitis (2/5), IgA deficiency and cow's milk intolerance $(1 / 5)$, atopic dermatitis $(1 / 5)$, or food intolerance $(1 / 5)$. The proximal jejunal mucosa showed a patchy lesion with moderate-low grade atrophy in three of five patients, including the two patients with gastritis and duodenitis and the patient affected by food intolerance. By immunohistochemistry in 2/5 patients, both intraepithelial CD3+ and lamina propria CD25+ cells were increased. In $1 / 5$ patients only intraepithelial CD3+ cells and in $2 / 5$ only lamina propria CD25+ cells were increased. None showed increased intraepithelial $\gamma \delta+\mathrm{T}$ cells and thus it is unlikely they had latent CD. ${ }^{12}$

For ex vivo challenge studies, six adult CD patients (two men, four women) aged 15-44 years (median 30.5) diagnosed on the basis of ESPGHAN criteria and eight normal controls (four men, four women) aged 19-60 years (median 39) investigated for upper abdominal complaints were enrolled. Five CD patients were on a gluten free diet for a median period of eight years (range 1-12) while one patient confirmed low compliance with this diet. All patients were recruited after appropriate local ethics committee approval and informed consent was obtained. Jejunal mucosa was histologically normal in both groups except for the untreated CD patient with atrophy, crypt hyperplasia, and increased intraepithelial lymphocyte infiltration. In the control group, 3/8 subjects were positive for gastritis and Helicobacter pylori. From each patient four biopsy specimens from the proximal jejunum were obtained by gastroduodenal endoscopy and placed immediately in ice chilled saline solution and processed within 30 minutes for in vitro organ culture experiments.

METHODS

In vitro organ culture experiments

Mucosal specimens were cultured principally as described elsewhere. ${ }^{14}$ Briefly, biopsies were placed on a stainless steel mesh with the mucosal face upwards in the central well of an organ culture dish in Trowell $(6.5 \mathrm{ml}) /$ NCTC$135(2.5 \mathrm{ml})$ medium supplemented with $10 \%$ fetal calf serum, penicillin $(100 \mathrm{U} / \mathrm{ml})$, and streptomycin $(100 \mu \mathrm{g} / \mathrm{ml})$ (Life TechnologiesGibco BRL, Milan, Italy) in the presence or absence of a peptic-tryptic digest (Frazer III fraction) of gliadin (Sigma, Milan, Italy) at 1 $\mathrm{mg} / \mathrm{ml}$. The dishes were placed in a sterile anaerobic jar which was gassed with $95 \% \mathrm{O}_{2} /$ $5 \% \mathrm{CO}_{2}$ and incubated at $37^{\circ} \mathrm{C}$. Biopsies at time 0 (baseline) and after eight hours of culture were snap frozen and stored at $-80^{\circ} \mathrm{C}$ for RT-PCR analysis.

\section{RNA standards for quantitative RT-PCR}

Plasmids pHCQ1 (provided by Dr MF Kagnoff, Department of Medicine, University of California, San Diego, USA) and pMBEK encoding the sequence of interferon $\gamma(\mathrm{IFN}-\gamma)$ and KGF, respectively, were used for quantitative RT-PCR, as described previously. ${ }^{815}$ To generate standard RNA molecules, plasmids were linearised with HindIII and transcribed in vitro using T7 RNA polymerase under conditions recommended by the supplier (Promega, Biotech, Milan, Italy).

\section{$R N A$ isolation and competitive quantitative} RT-PCR

Total tissue RNA was extracted from whole mucosal jejunal biopsies using the Trizol reagent (Gibco Life Technologies, Milan, Italy) according to the manufacturer's instructions and quantified at $260 \mathrm{~nm}$. The integrity of the RNA was checked by agarose gel electrophoresis. A constant amount of total RNA $(1 \mu \mathrm{g})$ and serial 10-fold dilutions of standard RNA molecules (1 pg to $0.1 \mathrm{fg}$ ) were co-transcribed into complementary cDNA in a $20 \mu \mathrm{l}$ reaction mixture containing $50 \mathrm{mM}$ Tris, $\mathrm{pH} 8.3,75 \mathrm{mM} \mathrm{KCl}, 3 \mathrm{mM}$ $\mathrm{MgCl}_{2}, 500 \mu \mathrm{M}$ each of dATP, dCTP, dTTP, and dGTP (Pharmacia Biotech, Milan, Italy), $10 \mathrm{mM}$ DTT, $0.5 \mu \mathrm{g}$ oligo $(\mathrm{dT})_{12-18}$ (Pharmacia Biotech) and 100 U M-MLVRT (Gibco Life Technologies). PCR was performed with $5 \mu \mathrm{l}$ of cDNA in $50 \mu$ of $20 \mathrm{mM}$ Tris $\mathrm{HCl}, \mathrm{pH} 8.4,50$ $\mathrm{mM} \mathrm{KCl}, 1.5 \mathrm{mM} \mathrm{MgCl}_{2}$ (for KGF), or $2 \mathrm{mM}$ $\mathrm{MgCl}_{2}$ (for IFN- $\gamma$ ), $200 \mu \mathrm{M}$ each of dATP, dCTP, dTTP, and dGTP, and $30 \mathrm{pM}$ of $5^{\prime}$ and 3' primers. PCR primers, amplification conditions, and molecular weights of standard and target molecules have been described elsewhere. ${ }^{8}{ }^{15}$ PCR products were visualised on a $2 \%$ agarose gel using Vistra-Green dye (Amersham International, Milan, Italy). Densitometric analysis of fluorescent bands was carried out on a STORM-860 analyser using ImageQuant software (Molecular Dynamics, Sunnyvale, California, USA). The ratio of standard/target RNA was plotted against the starting number of standard RNA molecules on a double logarithmic scale to determine the copy number in each sample. The data were presented as number of transcripts/ $\mu$ g total RNA.

Gluten challenge of mucosal CD4+ T cell clones Gut derived HLA-DQ restricted and gluten reactive $\mathrm{T}$ cell clones and lines were generated as detailed elsewhere. ${ }^{16}$ Two different gluten 


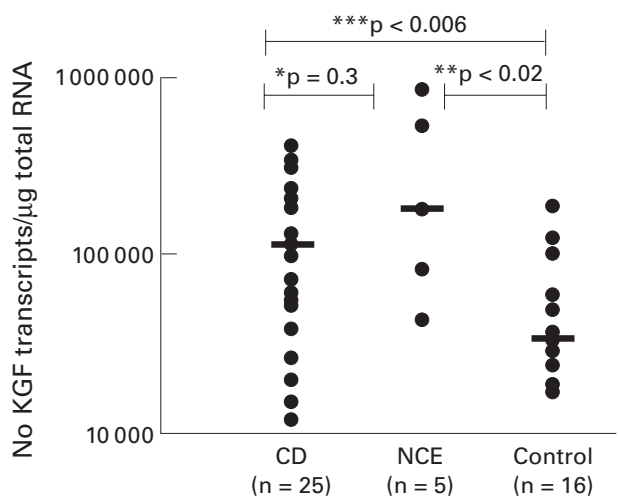

Figure 1 Keratinocyte growth factor $(K G F) m R N A$ transcripts in whole small intestinal biopsies from patients with coeliac disease (CD), non-coeliac enteropathy (NCE), and normal controls. Bars represent median $K G F m R N A$ transcripts. ${ }^{\star \star \star} C D$ versus controls, $p<0.006 ;{ }^{\star} N C E$ versus controls, $p<0.02 ;{ }^{\star} C D$ versus NCE, $p=0.3$

reactive CD4+ $\mathrm{T}$ cell clones and two CD4+ $\mathrm{T}$ cell lines were challenged in vitro with phorbol myristate acetate $\left(10^{-8} \mathrm{M}\right)$ plus immobilised anti-CD3 antibodies $(10 \mu \mathrm{g} / \mathrm{ml})$ coated on Dynabeads M450 (Dynal, Oslo, Norway) or with a peptic-tryptic digest of gliadin at $3 \mathrm{mg} / \mathrm{ml}$. Ebstein-Barr virus transformed B cell lines were used as antigen presenting cells. For each experiment, $1 \times 10^{5}$ Ebstein-Barr virus transformed B cells were incubated with $1 \times 10^{5}$ $\mathrm{T}$ cells in RPMI medium supplemented with
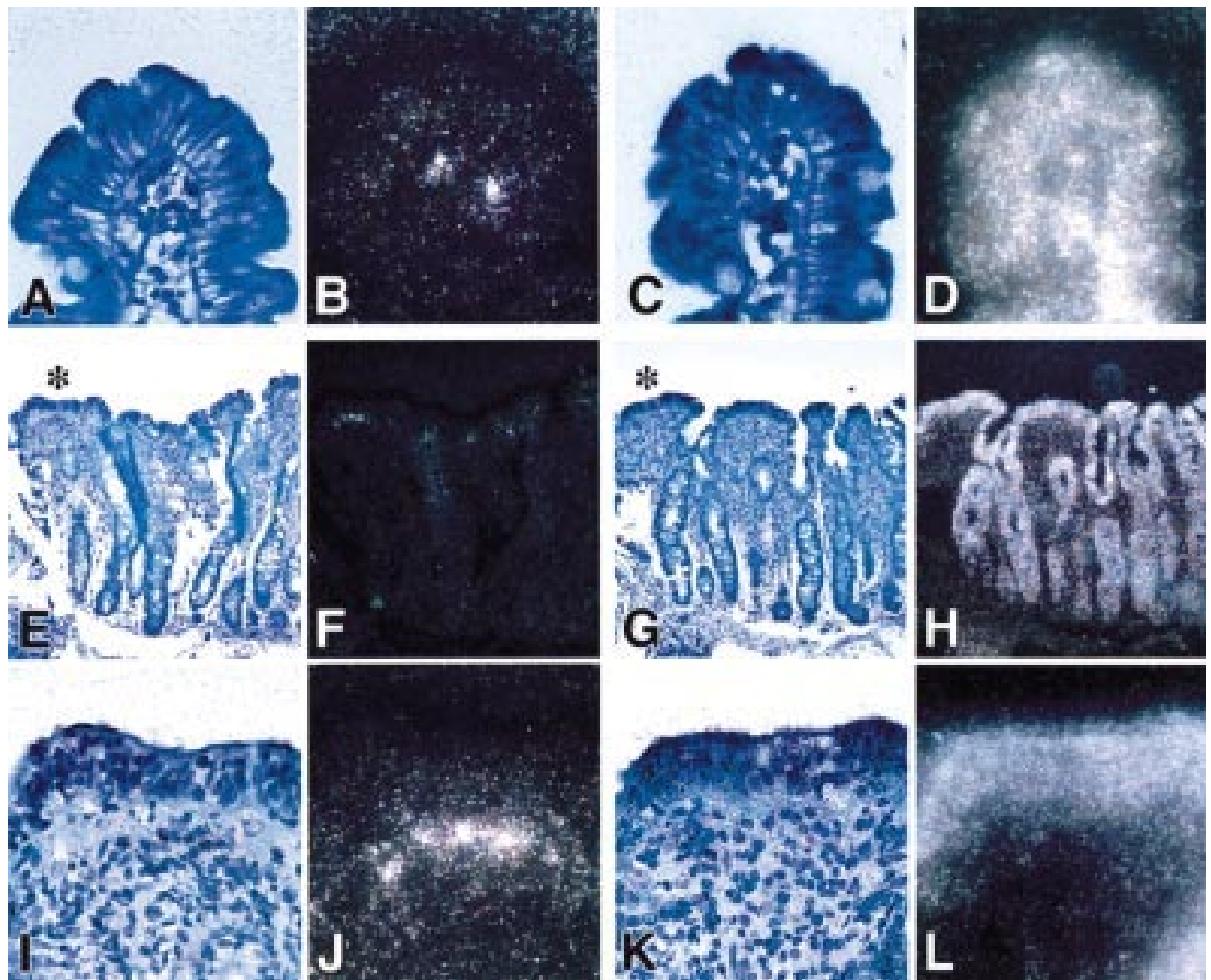

Figure 2 Detection of keratinocyte growth factor (KGF) mRNA by in situ hybridisation. $(A, B)$ and $(C, D)$ represent light/dark images of a control section hybridised with antisense probes to $\operatorname{KGF} m R N A(A, B)$ and to $\beta$-actin $(C, D)$ as a positive control at a magnification of 50x. Very few KGF transcripts were detectable in control sections below the tip of the villi. $(E)$ and $(F)$ show light and dark field images, respectively, at $20 \times$ magnification stained for KGF In (I) and (F) at $50 \times$ magnification the flat villi indicated by an asterisk in (E) are shown in more detail. KGF positive hybridising cells are distributed in the subepithelial region of the lamina propria below the tip of the flattened villi. $(G, H)(20 \times)$ and $(K, L)(50 \times)$ represent light $(G, K)$ and dark field $(H, L)$ images of the corresponding $\beta$-actin staining as a positive control. 


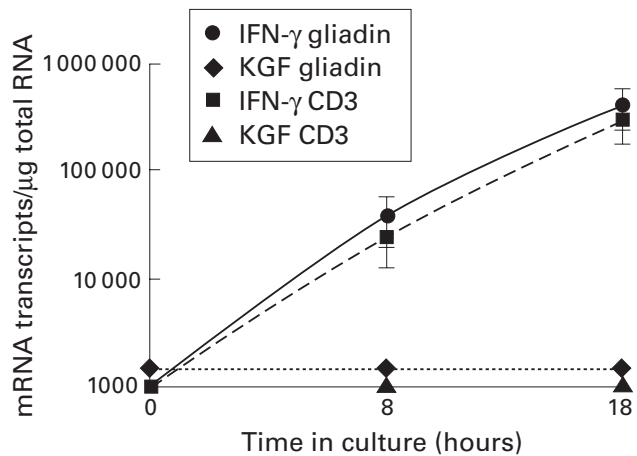

Figure 3 Number of keratinocyte growth factor (KGF) and interferon $\gamma(I F N-\gamma) m R N A$ transcripts in four gut derived gluten reactive CD4+ $T$ cell clones and lines challenged in vitro with a peptic-tryptic digest of gliadin or anti-CD3 antibodies for eight and 18 hours. Each point at the indicated time represents mean (SEM) values. KGF $m R N A$ expression was below the detection limit $(1000$ transcripts/ $\mu$ g total RNA) while IFN- $\gamma$ mRNA transcripts were increased after eight and 18 hours in the presence of gliadin or anti-CD3 antibodies (positive control).

independent samples and Wilcoxon signed rank test for paired samples.

\section{Results}

ANALYSIS OF KGF GENE EXPRESSION IN WHOLE BIOPSIES FROM CD PATIENTS

The abundance of KGF mRNA transcripts in control tissue was low (median 33105 transcripts/ $\mu$ g total RNA; range 2592-181 602). In untreated $\mathrm{CD}$ biopsies, KGF transcripts were markedly increased (median 112901 transcripts/ $\mu$ g total RNA; range 12273 404 570; $\mathrm{p}<0.006)$. In NCE, KGF mRNA transcripts were also abundant (median 177 025; 95\% confidence interval 42956 $831332 ; \mathrm{p}<0.02)$ and at a level not significantly different from that in CD patients $(p=0.3)$ (fig 1$)$. As an indication of ongoing inflammation, IFN- $\gamma$ mRNA transcripts were also measured and these were significantly upregulated in CD compared with normal and non-coeliac inflamed mucosa $(\mathrm{p}<0.0001)$ (data not shown), confirming previous studies by Nilsen and coworkers. ${ }^{17}$

IN SITU HYBRIDISATION ANALYSIS

In sections of control small bowel, KGF mRNA was barely detectable with only few positive hybridising cells at the top of occasional villi (fig 2B, dark field image). In contrast, in coeliac mucosa, KGF mRNA positive cells were distributed in the lamina propria in the subepithelial region of the flattened villi (fig $2 \mathrm{~F}$, dark field image at $20 \times$ and fig $2 \mathrm{~J}$ at $50 \times$ magnification). No transcripts were detected in the pericryptal stroma. In particular, no KGF positive hybridising cells were seen within the epithelium. Sections hybridised with an antisense probe for $\beta$-actin as a positive control showed abundantly positive cells throughout the tissue in coeliacs (fig $2 \mathrm{H}, \mathrm{L}$ ) and controls (fig 2D). In previous studies, a sense KGF probe gave no specific pattern of hybridisation. ${ }^{89}$

ANALYSIS OF KGF AND IFN- $\gamma$ GENE EXPRESSION IN MUCOSAL CD4+ T CELL CLONES

Gluten reactive $\mathrm{CD} 4+\mathrm{T}$ cell clones and lines obtained from coeliac small intestinal lamina
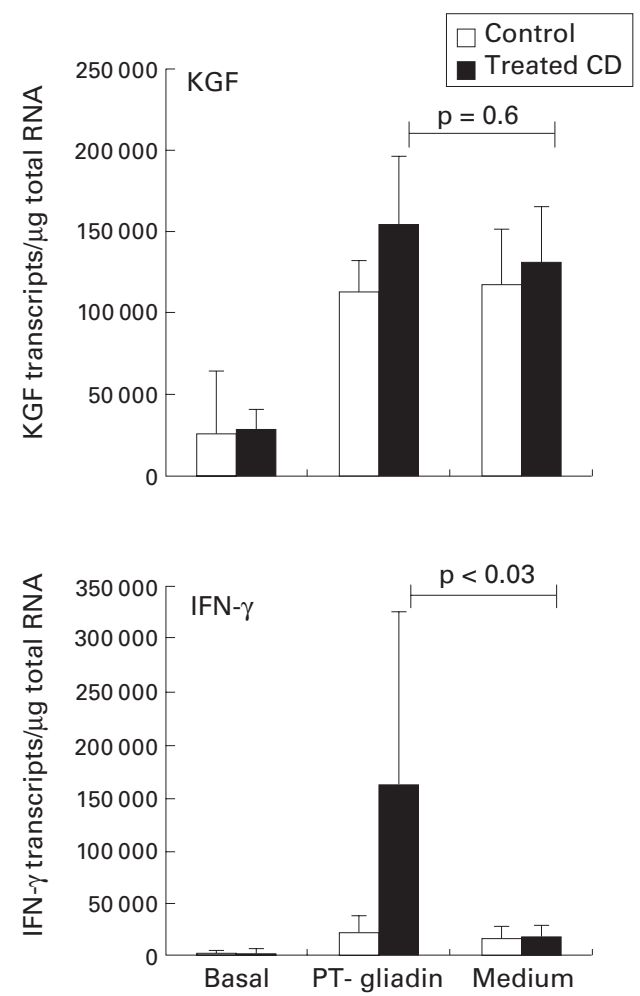

Figure 4 Keratinocyte growth factor (KGF) and interferon $\gamma(I F N-\gamma)$ mRNA transcripts measured by competitive quantitative RT-PCR in treated coeliac disease (CD) $(n=6)$ and control biopsies $(n=8)$ challenged in vitro with gliadin. Small intestinal biopsies were cultured for eight hours in the presence or absence of a peptic-tryptic (PT) digest of gliadin $(1 \mathrm{mg} / \mathrm{ml})$. Bars represent median (SEM). IFN- $\gamma$ mRNA transcripts were markedly induced by gliadin in coeliac mucosa compared with biopsies cultured in medium alone $(p<0.03)$. KGF $m R N A$ transcripts were increased in both coeliacs and controls, in the presence and absence of gliadin.

propria were challenged in vitro with a peptictryptic digest of gliadin or anti-CD3 antibodies. At two and four hours, IFN- $\gamma$ mRNA transcripts were not detectable (data not shown). However, a marked induction in IFN- $\gamma$ mRNA transcripts was observed at eight and 18 hours, while KGF transcripts were below the limit of detection (fig 3).

ANALYSIS OF KGF AND IFN- $\gamma$ GENE EXPRESSION IN CHALLENGED CD BIOPSIES

In treated coeliac biopsies challenged in vitro with gliadin, the number of IFN- $\gamma$ mRNA transcripts was markedly upregulated compared with biopsies cultured in medium alone $(\mathrm{p}<0.03)$ or with control biopsies challenged with gliadin. KGF mRNA transcripts were increased in both coeliac and control cultures compared with baseline levels, regardless of the presence of gliadin (fig 4).

\section{Discussion}

CD is characterised by small intestinal mucosal damage and nutrient malabsorption following dietary ingestion of prolamines in wheat, rye, and barley in genetically susceptible individuals. One of the hallmarks of the morphological features of the coeliac lesion is the atrophy of villi, accompanied by crypt hyperplasia and marked infiltration in the 
epithelium of $\mathrm{T}$ cells. ${ }^{12}$ Migration of $\mathrm{T}$ cells into the villous epithelium is the first immunopathological feature observed in jejunal mucosa of treated coeliac patients on gluten challenge. ${ }^{18}$ Gluten activated lamina propria $\mathrm{T}$ cells and culture explants from coeliac patients can produce proinflammatory cytokines of the Th1 type, dominated by IFN- $\gamma \cdot{ }^{17}$ In human fetal gut explants, experimental activation of $\mathrm{T}$ cells by anti-CD3 antibodies or polyclonal activators results in villus atrophy, crypt hyperplasia, and intraepithelial infiltration of lymphocytes, morphological features very similar to $\mathrm{CD} .{ }^{219}$ In human diseases, such as IBD and graft versus host disease, $\mathrm{T}$ cell mediated inflammation is followed by crypt hyperplasia. ${ }^{20}$ These data suggest that $\mathrm{T}$ cell activation drives crypt hyperplasia.

This study was undertaken to define the possible role of $\mathrm{KGF}$ in mediating crypt hyperplasia in $\mathrm{CD}$ and furthermore to clarify the cellular basis of KGF transcripts in CD. By competitive RT-PCR we found a marked increase in the number of KGF mRNA transcripts in both coeliac and non-coeliac enteropathy compared with control noninflamed mucosa. Our data are in line with other studies on gastrointestinal diseases, such as IBD, where the presence of inflammation and increased epithelial infiltration showed a parallel upregulation of this growth factor. ${ }^{78}$

Another important point addressed in our study was the cellular source of KGF transcripts in CD. We and others have previously shown that mesenchymal stromal cells of the lamina propria are a major source of $\mathrm{KGF}$ in IBD. ${ }^{78}$ In human fetal gut organ culture, where stimulation with bacterial superantigens drives $\mathrm{T}$ cell activation and morphological features very similar to $\mathrm{CD}, \mathrm{KGF}$ is also overexpressed by mesenchymal stromal cells. ${ }^{9}$ Nevertheless, in mice, activated $\gamma \delta \mathrm{T}$ cells of the skin and from the gut have been reported to make KGF, suggesting that IEL derived KGF may contribute to epithelial cell proliferation. ${ }^{10}$ In humans, expression of KGF by IELs remains unclear. Isolated $\gamma \delta$ IELs from human colonic inflamed mucosa have been reported to express $\mathrm{KGF}^{21}$ However, the signal observed by ribonuclease protection assay was weak and was not seen in all patients. There is the possibility that the weak signal was due to a few contaminating fibroblasts which express $\mathrm{KGF} \mathrm{mRNA}$ in abundance. ${ }^{89}$ As intraepithelial infiltration of $\gamma \delta$ IELs is a hallmark of the CD lesion, we investigated expression and localisation of KGF mRNA by in situ hybridisation. Interestingly, an increased number of positive cells were present but were confined to the lamina propria immediately below the mucosal epithelial layer of the flattened villi. No KGF producing cells were seen within the epithelium, despite an intense infiltrate of intraepithelial lymphoid cells. Our data thus indicate that intraepithelial $\gamma \delta \mathrm{T}$ cells of the gut mucosa do not produce KGF, at least not in levels detectable by in situ hybridisation, and are not the principal source of KGF mRNA in vivo. To extend these findings, we also analysed activated lamina propria $T$ cells (LPLs) for their capacity to synthesise KGF. CD4+ gluten reactive $\mathrm{T}$ cell clones and lines were isolated from the mucosa of coeliac patients and activated in vitro by anti-CD3 antibodies or a peptic-tryptic digest of gliadin. A time dependent increase in IFN- $\gamma$ mRNA was observed with no corresponding increase in $\mathrm{KGF}$ expression, suggesting that LPLs do not contribute to $\mathrm{KGF}$ expression in $\mathrm{CD}$. The present data are consistent with previous observations in IBD where KGF expression in the lamina propria was undetectable by immune cells. ${ }^{8}{ }^{21}$ Similarly, in our study there was no correspondence between the in situ hybridisation signal for $\mathrm{KGF}$ and localisation of $\mathrm{T}$ cells in the lamina propria. Our work thus indicates that overexpression of KGF in coeliac mucosa is not derived from T cells (LPL and IELs).

As observed in human IBD and in the fetal gut, high levels of KGF in coeliac mucosa may be produced by mesenchymal stromal cells. ${ }^{89}$ It has been suggested that immune mediated epithelial damage may lead to compensatory crypt hyperplasia ${ }^{2}$ but on the other hand it is also possible that $\mathrm{T}$ cell mediated chronic inflammation of the mucosa leads to activation of cytokines and growth factors responsible for mucosal remodelling. In fact, we had anticipated that localisation of KGF transcripts would be similar to Crohn's disease and ulcerative colitis - that is, throughout the lamina propria - and it was a surprise that they were located below the epithelium. However, other data suggest that the subepithelial layer is a site of tissue remodelling in active CD. Increases in MMP-1, MMP-3, and TIMP-1 mRNA expression in CD have been observed in fibroblasts and macrophages in the stroma underneath the surface epithelium and not in the pericryptal stroma. ${ }^{22}$

As in vivo challenge with gluten of treated coeliac patients is difficult, we attempted to study the early events induced by gluten in the coeliac treated mucosa by ex vivo organ culture. In fact, it may be that expression of KGF during the evolution of the lesion is different from the steady state in flattened mucosa. Previous studies have shown that in vitro challenge with gluten of treated CD biopsy specimens leads to activation of lamina propria $\mathrm{T}$ cells and macrophages, induces intraepithelial infiltration of lymphocytes, and expression on crypt epithelial cells of HLADR. ${ }^{23}$ We therefore challenged treated coeliac biopsies ex vivo with a peptic-tryptic digest of gluten and analysed mRNA expression for IFN- $\gamma$ and KGF after eight hours. High levels of IFN- $\gamma$ mRNA transcripts induced by gliadin were seen in coeliac biopsies as evidence of immunological activation. However, KGF transcripts were overexpressed in both control and coeliac biopsies cultured without or in the presence of gliadin compared with baseline levels snap frozen within 30 minutes after collecting the sample. This marked overexpression is probably a response to injury, as the biopsy is torn from the mucosa. 
Another interesting result was the finding that the abundance of KGF mRNA was also increased substantially in the NCE group. The molecular causes responsible for the mucosal changes were not known although there was some evidence of $\mathrm{T}$ cell activation in these patients (see methods). This suggests that $\mathrm{KGF}$ is involved in epithelial proliferation driven by $T$ cell mediated inflammation, regardless of the stimulus. This is a very similar situation to that of tumour necrosis factor $\alpha$ in inflamed colonic mucosa where tumour necrosis factor $\alpha$ secreting cells are increased, regardless of the cause of the inflammation. ${ }^{24}$

In conclusion, in $\mathrm{CD}$, as in other forms of gut inflammation characterised by crypt hyperplasia, KGF mRNA is overexpressed. Our data indicate that $\mathrm{KGF}$ is not produced by lamina propria $\mathrm{T}$ cells or intraepithelial $\gamma \delta \mathrm{T}$ cells. It is likely that in $\mathrm{CD}, \mathrm{KGF}$ expression is induced by proinflammatory cytokines in a paracrine and/or autocrine fashion and is involved in mucosal remodelling and crypt hyperplasia.

This study was carried out with financial support from the Commission of the European Communities, specific RTD programme "Quality of Life and Management of Living Resources", QLK1-CT-1999-00037, Evaluation of the prevalence of $\mathrm{CD}$ and its genetic components in the European population. It does not necessarily reflect its views and in no way anticipates the Commission's future policy in this area. The work was also partly supported by "Istituto Superiore di Sanita': Sorveglianza degli effetti nocivi da alimenti: intolleranza ai cereali (Convenzione 98/JK/T3)" and "MURST-PRIN: Citochine e patogenesi del danno mucosale nella malattia coeliaca", by the Wellcome Trust, the special trustees of St Bartholomew's Hospital, and the Crohn's in Childhood Research Association.

1 MacDonald TT, Bajaj-Elliott M, Pender SLF. T cells orchestrate intestinal mucosal shape and integrity. Immunol Today 1999;20:505-10.

2 MacDonald TT, Spencer J. Evidence that activated mucosal $\mathrm{T}$ cells play a role in the pathogenesis of enteropathy in human small intestine. 7 Exp Med 1988;167:1341-9.

3 Murphy MS. Growth factors and the gastrointestinal tract. Nutrition 1998;14:771-4.

4 Yasunaga Y, Shinomura Y, Kanayama S, et al. Increased production of interleukin 1 beta and hepatocyte growth production of interleukin 1 beta and hepatocyte growth
factor may contribute to foveolar hyperplasia in enlarged factor may contribute to foveolar
fold gastritis. Gut 1996;39:787-94

5 Finch PW, Rubin JS, Miki T, et al. Human KGF is FGF-related with properties of a paracrine effector of epithelial cell growth. Science 1989;245:752-5.

6 Housley RM, Morris CF, Boyle W, et al. Keratinocyte growth factor induces proliferation of hepatocytes and epithelial cells throughout the rat gastrointestinal tract. $\mathcal{F} \mathrm{Clin}$ Invest 1994;94:1764-77.
7 Brauchle M, Madlener M, Wagner AD, et al. Keratinocyte growth factor is highly overexpressed in inflammatory growth factor is highly overexpressed in
bowel disease. Am $\mathcal{F}$ Pathol 1996;149:521-9.

8 Bajaj-Elliott M, Breese E, Poulsom R, et al. Keratinocyte growth factor in inflammatory bowel disease. Am $\mathcal{F}$ Pathol 1997;151:1469-76.

9 Bajaj-Elliott M, Poulsom R, Pender SLF, et al. Interactions between stromal cell-derived keratinocyte growth factor and epithelial transforming growth factor in immunemediated crypt cell hyperplasia. F Clin Invest 1998;102: 1473-80.

10 Boismenu R, Havran WL. Modulation of epithelial cell growth by intraepithelial $\gamma \delta \mathrm{T}$ cells. Science 1994;266: $1253-5$.

11 Halstensen TS, Scott H, Brandtzaeg P. Intraepithelial T cells of the TcR $\gamma / \delta+$ CD 8 - and V $\delta 1 / J \delta 1+$ phenotypes are increased in celiac disease. Scand F Immunol 1989;30:66572.

12 Spencer J, Isaacson PG, MacDonald TT, et al. Gamma/ delta $\mathrm{T}$ cells and the diagnosis of celiac disease. Clin Exp Immunol 1991;85:109-13.

13 Walker-Smith JA, Guandalini S, Schmitz J, et al. Revised criteria of diagnosis of coeliac disease. Arch Dis Child 1990; 65:909-11.

14 Fais S, Maiuri L, Pallone F, et al. Gliadin induced changes in the expression of MHC-class II antigens by human small intestinal epithelium. Organ culture studies celiac disease mucosa. Gut 1992;33:472-5.

15 Jung HC, Eckmann L, Yang SK, et al. A distinct array of proinflammatory cytokines is expressed in human colon epithelial cells in response to bacterial invasion. 7 Clin Invest 1995;95:55-65.

16 Lundin KE, Scott $\mathrm{H}$, Hansen $\mathrm{T}$, et al. Gliadin-specific, HLA-DO (alpha $1^{\star} 0501$, beta $1^{\star} 0201$ ) restricted T cells isolated from the small intestinal mucosa of celiac disease patients. F Exp Med 1993;178:187-96.

17 Nilsen EM, Jahnsen FL, Lundin KEA, et al. Gluten induces an intestinal cytokine response strongly dominated by interferon gamma in patients with celiac disease. Gastroenterology 1998;115:551-63.

18 Brandtzaeg P, Halstensen TS, Hvatum M, et al. The serological and mucosal immunological basis of celiac disease. In: Walker WA, Harmatz PR, Wershil BK, eds. Immunophysiology of the gut. Bristol-Myers Squibb/Mead fohnson Nutrition Symposia, vol 11. London: Academic Press, 1993: 295-333.

19 Monk T, Spencer J, Cerf-Bensussan N, et al. Stimulation of mucosal T cells in situ with anti-CD3 antibody: Location of the activated $\mathrm{T}$ cells and their distribution within the mucosal microenvironment. Clin Exp Immunol 1988;74: 216-22.

20 MacDonald TT. The role of activated T lymphocytes in gastrointestinal disease. Clin Exp Allergy 1990;20:247-52.

21 Finch PW, Cheng AL. Analysis of the cellular basis of keratinocyte growth factor overexpression in inflammatory bowel disease. Gut 1999;45:848-55

22 Daum S, Bauer U, Foss H-D, et al. Increased expression of mRNA for matrix metalloproteinases- 1 and -3 and tissue inhibitor of metalloproteinases-1 in intestinal biopsy specimens from patients with celiac disease. Gut 1999;44:17-25.

23 Maiuri L, Picarelli A, Boirivant M, et al. Definition of the initial immunological modifications upon in vitro gliadin
challenge in the small intestine of celiac patients. Gastroenterology 1996;110:1368-78.

24 Breese EJ, Michie CA, Nicholls SW, et al. Tumor necrosis factor- $\alpha$ producing cells in the intestinal mucosa of children with inflammatory bowel disease. Gastroenterology 1994; 106:1455-6. 